\title{
HOW DOES CORPORATE SOCIAL RESPONSIBILITY IMPACT BANKING EFFICIENCY: A CASE IN CHINA
}

\section{Ning Zhu, Jelena Stjepcevic, Tomas Baležentis, Zhiqian Yu, Bing Wang}

\section{Introduction}

The concept of corporate social responsibility (CSR) drew much attention globally as economic growth was followed by such social problems as an increasing gap between the rich and the poor, cultural conflicts, and environmental degradation. Having acknowledged the importance of the latter challenges, the United Nations officially launched the "Global Compact" project in 2000 , thereby calling the enterprises for commitments towards social responsibility in the areas of human rights, labor standards, and environmental protection, among other issues. As an important actor in the global economic development, the banking sector also became aware of huge social costs associated with unsustainable economic growth, and recognized its responsibilities in such areas as an active reduction of social inequality and environmental degradation. Thus it is important to analyze the impact of commitments towards CSR upon banking performance.

Indeed, most of the previous studies, discussing the impacts of CSR, were focused on the link between CSR and corporate financial performance (CFP), see, e.g., Paul \& Siegel (2006). Furthermore, the parametric techniques were the most widely applied ones in the area (McWilliams \& Siegel, 2000; Wu \& Shen, 2013). One can find the four contradictory conclusions regarding the impact of CSR upon CFP in the literature, namely a positive impact (OheneAsare \& Asmild, 2012), a negative impact (Winchester et al., 2008), an arbitrary impact (Lee \& Park, 2009), and no impact (Soana, 2011). Based on the previous studies, we aim to verify the link between CSR and CFP by utilizing a nonparametric approach. Specifically, this paper attempts to re-examine the topic in Chinese banking sector.

Data envelopment analysis (DEA) is a celebrated nonparametric approach enabling one to evaluate firm performance in relative terms. The latter technique features certain advantages over the parametric approach due to less restrictive assumptions regarding the functional form of a representation of the underlying technology. However, to the best of our knowledge, there have been only a handful of studies applying DEA to investigate the link between CSR and CFP in banking. Furthermore, contrary to the two-stage DEA framework, which involves a parametric regression (Vitaliano \& Stella, 2006; Ohene-Asare \& Asmild, 2012), we utilize a fully nonparametric approach, viz., conditional DEA framework. In our setting, CSR is treated as an environmental variable to investigate its impact on efficiency of Chinese banking sector.

\section{Literature Review}

\subsection{The Origins of Corporate Social Responsibility}

Sheldon (1923) was among the first to establish the concept of CSR, whereas Bowen (1953) defined the modern version of CSR by highlighting the social value and the social goal. In the earlier studies, CSR was widely discussed in fields of law and ethics with a controversy over the underlying rationale for contributing to CSR, cf., in particular, the famous Berle-Dodd Dialogue in the 1930s. Since the late 1960s, the argument has emerged among economists as well. Friedman (1970) argued that CSR would increase production cost and thus result in a reducing competitiveness of corporations. Therefore, the sole "social responsibility" of a manager should be achieving profit maximization for a corporation. However, Freeman (1984) developed the stakeholder theory, which treated CSR as a benefit not only for shareholders, but also for employees, customers, government, and even environment. 
Furthermore, he argued that CSR would bring a positive effect for reducing transaction cost for corporations. Sheikh (1996) suggested considering profit optimization as the corporate objective in lieu of profit maximization.

As the debate continued, the topic of linkage between CSR and CFP was widely discussed. Yet, a rich body of literature did not yield a definite conclusion. As Carroll (2000) put it, CSR is a complex phenomenon and, thus, various instances of links between CSR and CFP are possible.

Roman et al. (1999) surveyed 52 studies, analyzing the link between CSR and CFP. It turned out that positive results had been reported in 33 papers, insignificant results - in 14 papers, and negative results - in 5 papers. Margolis \& Walsh (2003) further increased the number of empirical studies covered up to 127 , and the results suggested that there had been 54 papers reporting a positive relationship, 20 papers reporting an arbitrary relationship, 28 papers reporting an insignificant relationship, and 7 papers reporting a negative relationship. The aforementioned reviews suggest that most of the studies support a positive link.

Bragdon and Marlin (1972) were the first to study the link between CSR and CFP. Noteworthy, a positive result was obtained in the latter study. Moskowits (1972) then applied a reputation index to explain the positive impact. Afterwards, the corporate reputation emerged as a popular point to support the positive link between CSR and CPF (Wu \& Shen, 2013). Fombrun \& Shanley (1990) asserted that higher contribution to CSR induces higher corporate reputation, which, in turn, can attract more customers, improve transactions, and increase loyalty. Furthermore, Bushman and WittenbergMoerman (2012) related high reputation to high profitability. The positive link was also explained in terms of a rapid cost reduction and eased regulation, which could eventually lead to an increase in equity value (Bird et al., 2007).

Noteworthy, Roman et al. (1999) reported $66 \%$ of the studies surveyed as having found a positive link between CSR and CFP, whereas the corresponding figure dropped to $42.5 \%$ in Margolis adn Walsh (2003). These findings imply a possible divergence in terms the impact of CSR upon CFP. Indeed, Margolis et al. (2009) affirmed this trend following a further research into the issue. A recent review by $\mathrm{Wu}$ and Shen (2013) defined the three different motives to conduct CSR in banking along with their impacts: altruism is related to a negative effect of CSR on CFP, strategic choice is related to a positive effect, and greenwashing has no significant effect.

Weber (2008) showed that both qualitative (e.g., case studies) and quantitative (e.g., portfolio analysis, event studies, and multiple regression analysis) methods were applied for empirical research on CSR. Soana (2011) also applied content analysis, questionnaire survey, reputation measure, one-dimensional indicator and ethical rating to investigate the links between CSR and CFP.

As regards the applications of frontier techniques for analysis of CSR and CFP, the parametric approach has been the primal technique in the literature. However, thanks to less restrictive assumptions, a nonparametric approach, e.g., DEA, might be an appropriate tool for an empirical analysis. However, few studies have applied it to test the link between CSR and CFP either directly or indirectly. Vitaliano \& Stella (2006) used an input-oriented DEA model to evaluate the cost efficiency of CSR and non-CSR saving banks in the U.S. and treated the inefficiency as a shadow price of CSR. Ohene-Asare and Asmild (2012) developed a conventional DEA-based intermediation model, incorporating contribution to CSR, to evaluate the efficiency of Ghanaian banks. They analyzed the differences between efficiency scores obtained by the virtue of models including CSR and those without CSR. It was found out that CSR had a significant impact on banking efficiency. Subsequently, a parametric regression was applied to check the link between CSR and CFP, which rendered a positive result. However, due to OheneAsare and Asmild (2012), several aspects need to be questioned. In the first stage, the aforementioned study interpreted CSR as an output variable and thus implicitly established a positive link between CSR and CFP. Although CSR was treated as an environmental variable later on, the analysis was based on a parametric approach. In this case, one needs to consider certain caveats pertinent to the second stage analysis, as per Daraio et al. (2010).

\subsection{Conditional Efficiency}

There are two main strands of approaches for analysis of the impact of the exogenous environmental variables upon efficiency, namely 
single-stage and two-stage approaches. The single-stage approach treats the environmental variables as non-discretionary inputs or outputs when defining the technology. The two-stage approach treats the environmental variables as independent variables in a regression. However, there are some obvious drawbacks pertinent to the two conventional approaches. As regards the single-stage analysis, the primal problem is a classification of the environmental variables in terms of their role in the production process. The two-stage analysis draws certain critique as it involves parametric techniques (in its conventional form) and a crucial requirement of separability among environmental variables and controlled variables (inputs and outputs) arises. Even though Simar and Wilson (2007) developed the double bootstrap procedure to circumvent the problem of serial correlation in the regression, two-stage approach might not provide a meaningful inference in case the condition of separability is not fulfilled (Daraio et al., 2010).

Besides the two abovementioned conventional approaches, Cazals et al. (2002) extended their probabilistic order- $m$ approach to so-called conditional efficiency measurement demonstrating how to take exogenous environmental variables into account. Daraio and Simar (2005) further systematically developed the standard conditional efficiency approach on the basis of Cazals et al. (2002), but it was confined to a non-convex technology and continuous environmental variables. Later on, Daraio and Simar (2007) extended the nonconvex nonparametric approach to a convex version, while Bădin et al. (2010) and De Witte and Kortelainen (2013) considered discrete environmental variables based on Li and Racine's (2008) kernel function. Daraio and Simar (2014) generalized conventional conditional distance function to conditional directional distance function, and, additionally, considered the case of sub-vector directional efficiency analysis.

There are two intertwisted questions, important to the conditional efficiency approach. The first one is bandwidth selection. Daraio and Simar (2005) applied a k-nearest neighbor method for bandwidth selection, yet it does not provide an optimal bandwidth to analyze the impact of environmental variables, and it does not fully satisfy the separability condition. The most widely applied approach for bandwidth selection is that applied by Bădin et al. (2010), namely the least squares cross validation (LSCV) of Hall et al. (2004). Daraio and Simar (2014) suggested directly employing the optimal bandwidth selection by Hall et al. (2004), which is suitable for non-oriented measures. Another important aspect is the impact of environmental variables. Daraio and Simar (2005) described how to analyze the effect of environmental variables based on a nonparametric kernel regression, where the ratio of conditional to unconditional efficiency scores is a depended variable. In order to accommodate the conditional directional distance function, Daraio and Simar (2014) considered a difference rather than ratio.

Conditional efficiency studies covered such fields as mutual funds (Daraio \& Simar, 2005), education (De Witte \& Kortelainen, 2013), and environmental efficiency (Halkos et al., 2016), among others. Indeed, many previous papers were based on the order- $m$ approach. As the conditional efficiency framework can be technically applied along with any appropriate estimator, recent empirical studies, based on conditional efficiency measures, involved some other efficiency models. For instance, Halkos et al. (2014) treated partiality, corruption, and effectiveness of government services as environmental variables identifying governance quality and thus analyzed their impact upon regional environmental performance. Furthermore, several types of pollution were treated as bad outputs by the means of the conditional directional distance function. Baležentis and De Witte (2015) extended multidirectional efficiency analysis (MEA) by Bogetoft and Hougaard (1999) to conditional efficiency framework, and further empirically measured the efficiency of Lithuanian family farms with respect to their operational environment.

\section{Methodology}

\subsection{Conditional Efficiency Measures}

The conditional efficiency framework of Cazals et al. (2002) and Daraio and Simar (2005) is applied to analyze the impact of the environmental variables upon the relative performance. In other words, environmental variables may alter the production frontier and thus enable to obtain more reasonable efficiency scores for individual DMUs.

Besides inputs $X=x \in R_{+}^{n}$, good outputs $Y=y \in R_{+}^{m}$, and environmental variables $Z=z \in R_{+}^{s}$, we extended original conditional 
efficiency model to additionally include bad outputs $B=b \in R_{+}^{l}$ into account. However, differently from Halkos et al. (2015), we define a modified joint probability function considering bad outputs as follows:

$$
\begin{aligned}
& H_{X Y B \mid Z}(x, y, b)=\operatorname{Prob}(X \leq x, Y \geq y, \\
& B \leq b \mid Z=z)
\end{aligned}
$$

Due to the characteristics of bad outputs, $b$, it is impossible to directly decompose Eq. (1) according to the Bayes rule (see Daraio \& Simar, 2005 , for more details), but it is still possible to obtain the conditional survivor function in the following manner (Daraio \& Simar, 2014):

$$
\hat{S}_{Y, B \mid X, Z}(y, b \mid x, z)=\frac{\sum_{k=1}^{K} I\left(X_{k} \leq x, Y_{k} \geq y, B_{k} \leq b\right) K_{h}\left(\frac{Z_{k}-z}{h}\right)}{\sum_{k=1}^{K} I\left(X_{k} \leq x\right) K_{h}\left(\frac{Z_{k}-z}{h}\right)}
$$

where $K_{h}(\cdot)$ is the kernel function, and $h$ is the bandwidth. Note that the bandwidth is critical to determine the smoothness of the estimated density. We select the appropriate bandwidth, $h$, according to Hall et al. (2004) in our framework. For orientations optimizing either good or bad output only, we modify the denominator of Eq. 2 accordingly. Specifically, for model, aimed at increasing the good output, we only look at observations, which consume $x$ quantity of input at most and produce $b$ quantity of bad output at most.

\subsection{Multi-Directional Efficiency Analysis}

Bogetoft and Hougaard (1999) first theoretically proposed the theoretical preliminaries for the new potential improvement approach and, subsequently, Asmild et al. (2003) developed a DEA-based efficiency measure, namely Multidirectional Efficiency Analysis (MEA). Unlike the conventional Farrell framework, MEA employs benchmarking against an ideal point, which is endogenously determined by operational environment, rather than a radial movement towards the origin. Given the output-oriented conditional efficiency framework, the ideal point for an individual observation, $k$, is obtained as:

$$
\begin{array}{ll}
\text { s.t. } & y_{k^{\prime} m}^{t}{ }^{*}(x, y, b)=\max \varphi_{k^{\prime} m}^{t} \\
& \sum_{k \mid K_{h}\left(z^{0}, z^{k}\right) \geq \varepsilon} \lambda_{k}^{t} x_{k n}^{t} \leq x_{k^{\prime} n}^{t}, n=1, \ldots, N \\
& \sum_{k \mid K_{h}\left(z^{0}, z^{*}\right) \geq \varepsilon}^{t} \lambda_{k}^{t} y_{k m}^{t} \geq \varphi_{k^{\prime} m}^{t},
\end{array}
$$

$$
\begin{aligned}
& \sum_{k \mid K_{k}\left(z^{0}, z^{k}\right) \geq \varepsilon} \lambda_{k}^{t} y_{k(-m)}^{t} \geq y_{k^{\prime}(-m)}^{t},-m=1, \ldots,(m-1),(m+1), \ldots, M \\
& \sum_{k \mid K_{h}\left(z^{0}, z^{k^{\prime}}\right) \geq \varepsilon} \lambda_{k}^{t} b_{k l}^{t}=b_{k^{\prime} l}^{t}, l=1, \ldots, L \\
& \lambda_{k}^{t} \geq 0, k, k^{\prime}=1, \ldots, K
\end{aligned}
$$

$$
\begin{aligned}
& b_{k^{\prime} l}^{t}{ }^{*}(x, y, b)=\min \eta_{k^{\prime} l}^{t} \\
& \text { s.t. } \sum_{k \mid K_{h}\left(z^{0}, z^{k}\right) \geq \varepsilon} \lambda_{k}^{t} x_{k n}^{t} \leq x_{k^{\prime} n}^{t}, n=1, \ldots, N \\
& \sum_{k \mid K_{k}\left(z^{0}, z^{k}\right) \geq \varepsilon} \lambda_{k}^{t} y_{k m}^{t} \geq y_{k^{\prime} m}^{t}, m=1, \ldots, M \\
& \sum_{k \mid K_{k}\left(z^{0}, z^{k}\right) \geq \varepsilon} \lambda_{k}^{t} b_{k l}^{t}=\eta_{k^{\prime} l}^{t} \\
& \sum_{k \mid K_{k}\left(z^{0}, z^{k}\right) \geq \varepsilon} \lambda_{k}^{t} b_{k(-l)}^{t}=b_{k^{\prime}(-l)}^{t},-l=1, \ldots,(l-1),(l+1), \ldots, L \\
& \lambda_{k}^{t} \geq 0, k, k^{\prime}=1, \ldots, K
\end{aligned}
$$

The two models given by Eqs. 3 and 4 can be solved jointly to arrive at optimization of both good and bad outputs. Following Asmild and Pastor (2010), the output-oriented slackfree MEA, based on the directional distance function, seeks to obtain the parameter $\beta^{t}$ with $\left(s_{k n}^{x t}, s_{k m}^{y t}, s_{k l}^{b t}\right)$ being a nonnegative slack set:

$$
\begin{aligned}
& \vec{D}(x, y, b)=\max \beta_{k^{\prime}}^{t} \\
& \text { s.t. } \quad \sum_{k \mid K_{k}\left(z^{0}, z^{k^{\prime}}\right) \geq \varepsilon} \lambda_{k}^{t} x_{k n}^{t}+s_{k^{\prime} n}^{x t}=x_{k^{\prime} n}^{t}, n=1, \ldots, N \\
& \sum_{k \mid K_{h}\left(z^{0}, z^{k}\right) \geq \varepsilon} \lambda_{k}^{t} y_{k m}^{t}-s_{k^{\prime} m}^{y t}=y_{k^{\prime} m}^{t}+\beta_{k^{\prime}}^{t}\left(\varphi_{k^{\prime} m}^{t}-y_{k^{\prime} m}^{t}\right), m=1, \ldots, M( \\
& \sum_{k \mid K_{h}\left(z^{0}, z^{k}\right) \geq \varepsilon} \lambda_{k}^{t} b_{k l}^{t}+s_{k^{\prime} l}^{b t}=b_{k^{\prime} l}^{t}-\beta_{k^{\prime}}^{t}\left(b_{k^{\prime} l}^{t}-\eta_{k^{\prime} l}^{t}\right), l=1, \ldots, L \\
& \quad \lambda_{k}^{t} \geq 0, s_{k^{\prime} n}^{x t} \geq 0, s_{k^{\prime} m}^{y t} \geq 0, s_{k^{\prime} l}^{b t} \geq 0, k, k^{\prime}=1, \ldots, K
\end{aligned}
$$

Subsequently, one can obtain the outputspecific MEA efficiency scores for individual observations as follows:

$$
\begin{aligned}
& e_{y k^{\prime} m}^{t}=\frac{y_{k^{\prime} m}^{t}}{y_{k^{\prime} m}^{t}+\beta_{k^{\prime}}^{t}\left(\varphi_{k^{\prime} m}^{t}-y_{k^{\prime} m}^{t}\right)+s_{k^{\prime} m}^{y t}} \\
& e_{b k^{\prime} l}^{t}=\frac{b_{k^{\prime} l}^{t}-\beta_{k^{\prime}}^{t}\left(b_{k^{\prime} l}^{t}-\eta_{k^{\prime} l}^{t}\right)-s_{k^{\prime} l}^{b t}}{b_{k^{\prime} l}^{t}}
\end{aligned}
$$

Furthermore, in order to ensure interpretability of the overall efficiency score, we employ the modified output-oriented slack-based measure (SBM), which ensures aggregation in the spirit of Tone (2001). The measure considers both desirable and undesirable outputs to calculate the overall efficiency score $e_{k}^{t}$ : 


$$
\begin{aligned}
& e_{k^{\prime}}^{t}=\frac{1}{1+\frac{1}{M+L}\left(\frac{\beta_{k^{\prime}}^{t}\left(\varphi_{k^{\prime} m}^{t}-y_{k^{\prime} m}^{t}\right)+s_{k^{\prime} m}^{y t}}{y_{k^{\prime} m}^{t}}+\right.} \\
& \overline{+\frac{\beta_{k^{\prime}}^{t}\left(b_{k^{\prime} l}^{t}-\eta_{k^{\prime} l}^{t}\right)+s_{k^{\prime} l}^{b t}}{b_{k^{\prime} l}^{t}}}
\end{aligned}
$$

Note that efficiency scores, defined in Eqs. $6-8$, are bounded at unity from above and approach the latter value in case of full efficiency. Due to different directions of optimization, Eq. 2 is defined in different ways. Therefore, in the conditional framework, we estimate separate MEA models rather than decompose Eq. 8.

\subsection{Impact of Environmental Variables to Efficiency}

Due to the non-radial nature of measures in Eqs. 6-8, the estimation of the effects of environmental variables, $z$, based on the ratio form is not appropriate, and, thus, a difference form is applied in accordance with Daraio and Simar (2014):

$$
Q^{z}=e(x, y, b \mid z)-e(x, y, b)
$$

In a fully nonparametric framework, a smooth nonparametric regression is employed to estimate the impact of environmental variables, $z$, on the difference of conditional and unconditional efficiency scores, i.e.:

$$
Q_{k}^{z}=f\left(z_{k}\right)+\varepsilon_{k}
$$

where $f\left(z_{k}\right)$ is the mean regression function, and $\varepsilon_{k}$ is the error term with $E\left(\varepsilon_{k} \mid z_{k}\right)=0$. However, instead of the mostly used local constant kernel regression of Nadaraya (1964) and Watson (1964), we employ a local linear regression for $f\left(z_{k}\right)$, which is less sensitive to boundary effects and can also simultaneously uncover the marginal effects of the environmental variables (Jeong et al., 2010; De Witte \& Kortelainen, 2013). The local linear model is based on the weighted minimization of errors:

$$
\min _{\{a, b\}} \sum_{k=1}^{K}\left(Q_{k}^{z}-\alpha-\left(z_{k}-z\right) \beta\right)^{2} K_{h}\left(z, z_{k}\right)
$$

Following Bădin et al. (2012) and Daraio and Simar (2014), the difference in Eq. 9 will increase with $z$ in case of the positive shift in the production frontier. However, in the context of weak disposability and SBM, the direction of shift cannot be described explicitly. Anyway, a positive trend in $Q^{z}$ against $z$ indicates an increasing productivity of the resources used with respect to input transformation into good and bad outputs.

Given firms operate in different environments, the condition of separability (cf. Simar \& Wilson, 2011) might not be fulfilled. In this case, regression on unconditional efficiency scores might not be meaningful. In order to measure the impact of $z$ variables upon the average efficiency we follow Bădin et al. (2012) and define a flexible regression model:

$$
\begin{aligned}
& e(X=x, Y=y, B=b \mid Z=z)= \\
& =\mu(z)+\sigma(z) \varepsilon
\end{aligned}
$$

where $E(\varepsilon \mid z)=0$ and $V(\varepsilon \mid z)=1, \mu(\cdot)$ measures the average effect of $z$ upon efficiency and $\sigma(\cdot)$ provides a measure of variance and thus accounts for heteroskedasticity. Following this setting, one can recover "pure" efficiency scores, which indicate the managerial ability to ensure efficiency given the environment defined by the observed values of $z$ variables. The "pure" efficiency can be estimated on the basis of the error term in Eq. 13:

$$
\varepsilon=\frac{e(x, y, b \mid z)-\mu\left(z_{s}\right)}{\sigma(z)}
$$

where $\sigma(\cdot)$ is estimated in lines with Bădin et al. (2012). In our setting, higher values of $\varepsilon$ are associated with higher "pure" efficiency.

\section{Data Used}

Due to data availability, the dataset applied comprises 64 observations which cover 13 major Chinese commercial banks during the period of 2008-2013, and the total assets of sample banks occupy more than $70 \%$ of those in the Chinese banking sector. The whole sample can be classified into the two groups: large commercial banks (LCB), which commonly include four state-owned commercial banks, and small-medium commercial banks (SMCB), which include joint stock commercial banks and city commercial banks. Data come from Annual Reports of Corporate Social Responsibility of each individual bank. The variables are deflated with base year 2008 . 


\subsection{The CSR Variable}

CSR is treated as an environmental variable in this study. This sub-section, therefore, presents the main concepts for measurement of CSR along with approach taken in our analysis.

Carroll (1979) gave a comprehensive definition of CSR, involving economic, legal, ethical, and discretionary responsibilities, whereas lots of recent CSR studies referred to the latest definition by McWilliams and Siegel (2001), which highlights the voluntary activities. However, due to available data, previous studies typically employed various subjective indicators for the CSR (e.g., McWilliams \& Siegel, 2001; Soana, 2011), whereas Ohene-Asare and Asmild (2012) further used an objective CSR variable, which can be measured in monetary terms. In this paper, we also employ a monetary objective variable as a CSR variable specific to the Chinese context.

The Shanghai Stock Exchange issued the Notice on Strengthening Corporate Social Responsibility of Listed Companies in 2008 and defined the concept of "social contribution value per share" (SCVPS). Following the definition, besides creating earning per share for shareholders, a listed company has a responsibility to increase tax revenue for government, offer reasonable pay for employees, pay regulatory loan interest to creditors, and raise charity donations. Meanwhile, the social cost, involving sewage charges and environmental violation fines, should also be considered when calculating the SCVPS. The SCVPS is, therefore, calculated as:

$$
\text { SCVPS }=\text { Earnings per share }+
$$

Taxes + Salaries + Interests + Donations - Social costs.

$$
\text { Equity }
$$

To put it otherwise, a listed company should raise awareness of performing responsibly not only in sense of improving its individual financial performance and protecting shareholders' interests, but also by taking into account noncommercial contributions to stakeholders, society, and environment. In general, the SCVPS can be decomposed into the two components, viz., economic responsibility, as represented by earnings per share, and purely social contribution, as represented by the rest of indicators. Given the former component corresponds to the very nature of commercial banks (i.e., pursuing for profit maximization), we treat it as a desirable output in our production model. The remaining part of SCVPS is directly related to bank's responsibility towards society and thus we define the CSR variable for our model as follows:

$$
\text { CSR }=\frac{\text { Taxes }+ \text { Salaries }+ \text { Interests }+ \text { Donations }- \text { Social costs }}{\text { Equity }}
$$

Indeed, we consider absolute input and output variables along with a relative $z$ variable (i.e., monetary value per share) to avoid multicollinearity.

\subsection{Input and Output Variables}

The production model comprises one input, one good output, and one bad (undesirable) output:

- Input: fixed assets (FA),

- Good output: net profit (NP),

- Bad output: non-performing loans (NPL).

The FA is a conventional input variable, associated with increasing opportunity costs (Berger \& Humphrey, 1997). Note that a contraction of fixed assets is often impossible for banks (Asmild \& Matthews, 2012). Therefore, we do not look at the input orientation in this study. Moreover, we do not include labor costs into the model as it is associated with salaries, which, in turn, are included in the CSR variable. Indeed, we have computed the Pearson correlation coefficient for FA and the number of employees as a proxy for labor costs. The results show that there exists a high positive correlation (0.945) significant at $1 \%$ level, which implies that ignoring labor costs is not to impact the measures of banking efficiency to a considerable extent. Another common input, the deposit, is not employed as well, because it is associated with interests in the CSR variable, and the Pearson correlation coefficient for FA and deposit is 0.962 significant at $1 \%$ level.

The NP is an explicit desirable output variable, and it is related to "earning per share" in the SCVPS. The undesirable output, namely NPL, played a critical role during the Chinese banking reform. In order to reduce the non-performing loans, Chinese commercial banks have constantly been improving risk management capabilities thereby enhancing willingness and ability for performing responsibly.

Tab. 1 presents the descriptive statistics for both operational variables (input and outputs) and environmental variable, CSR. As one can 


\begin{tabular}{l|r|r|r|r|r|r} 
& \multicolumn{1}{|c|}{ Max } & \multicolumn{1}{c|}{ Min } & \multicolumn{1}{c|}{ Mean } & \multicolumn{1}{c|}{ SD } & \multicolumn{1}{c}{ CV } & \multicolumn{1}{c}{ Growth } \\
\hline CSR & 6.65 & 0.77 & 2.52 & 1.61 & 0.64 & 0.268 \\
\hline FA & 144,403 & 1,703 & 44,139 & 48,638 & 1.10 & 0.003 \\
\hline NP & 231,054 & 2,260 & 61,139 & 61,662 & 1.01 & 0.057 \\
\hline NPL & 104,482 & 743 & 30,478 & 32,026 & 1.05 & -0.095 \\
\hline
\end{tabular}

Source: own

Note: SD - standard deviation, CV - coefficient of variation, Growth - average rate of growth; the dimension of CSR is CNY per share, and those of FA, NP, and NPL are million CNY.

note, CSR exhibits the smallest CV value (0.64) among all the variables, yet CSR grew at the highest rate of $26.8 \%$, which implies the CSR has become prevalent among banks in China. The values of the CV for operational variables are rather similar. FA features the lowest rate of growth $(0.3 \%)$, whereas NP shows the largest one $(5.7 \%)$, implying an increase in profitability; There is a negative rate of growth observed for NPL, $-9.5 \%$, due to banking reform in China, aimed at reducing NPLs.

\section{Empirical Analysis}

There are three conditional models utilized to analyze the impact of CSR (as measured per share) upon bank performance. Indeed, we focus on (i) output-oriented model with both good and bad outputs being optimized, (ii) output-oriented model with good output being optimized and bad output used to define the production frontier, and (iii) output-oriented model with bad output being optimized and good output used to define the production

\section{Tab. 2: Overall and output-specific efficiency scores}

\begin{tabular}{l|l|l|l}
\multicolumn{1}{c|}{ Bank } & \multicolumn{3}{c}{ Overall } \\
\hline & C & U & D \\
\hline ICBC & 0.89 & 0.61 & 0.28 \\
\hline CCB & 0.86 & 0.60 & 0.26 \\
\hline BC & 0.74 & 0.51 & 0.23 \\
\hline ABC & 0.75 & 0.52 & 0.23 \\
\hline BCM & 0.65 & 0.53 & 0.12 \\
\hline CMSB & 0.73 & 0.66 & 0.07 \\
\hline SPDB & 0.78 & 0.75 & 0.03 \\
\hline IB & 1.00 & 0.97 & 0.03 \\
\hline CMB & 0.78 & 0.69 & 0.09 \\
\hline CITIC & 0.70 & 0.68 & 0.02 \\
\hline BBJ & 0.84 & 0.84 & 0.00 \\
\hline BNJ & 0.74 & 0.74 & 0.00 \\
\hline SHB & 0.64 & 0.64 & 0.00 \\
\hline Mean & 0.77 & 0.66 & 0.11 \\
\hline Spearman & $0.614^{* * *}$ & \\
\hline
\end{tabular}

\begin{tabular}{c|c|c}
\multicolumn{3}{|c}{ NP } \\
\hline C & U & D \\
\hline 0.94 & 0.40 & 0.54 \\
\hline 0.93 & 0.40 & 0.53 \\
\hline 0.57 & 0.26 & 0.31 \\
\hline 0.58 & 0.27 & 0.31 \\
\hline 0.46 & 0.30 & 0.16 \\
\hline 0.63 & 0.52 & 0.11 \\
\hline 0.76 & 0.66 & 0.10 \\
\hline 1.00 & 0.98 & 0.02 \\
\hline 0.58 & 0.50 & 0.08 \\
\hline 0.64 & 0.59 & 0.05 \\
\hline 0.82 & 0.82 & 0.00 \\
\hline 0.53 & 0.53 & 0.00 \\
\hline 0.44 & 0.43 & 0.01 \\
\hline 0.68 & 0.49 & 0.19 \\
\hline $0.553^{\text {*** }}$ &
\end{tabular}

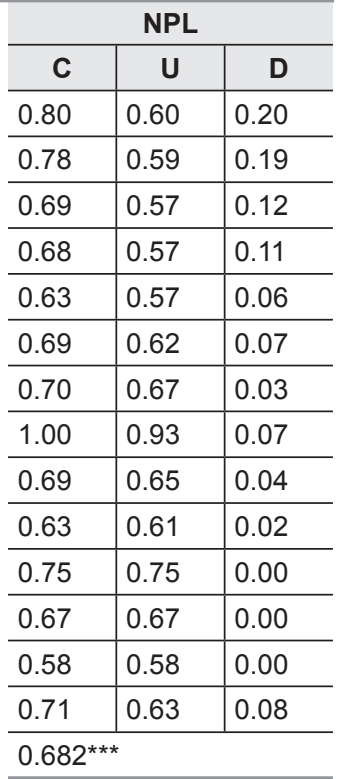

Notes: C - conditional efficiency; U - unconditional efficiency; D - difference between conditional and unconditional efficiencies; ${ }^{* * *}$ - significance at the $1 \%$ level; NP - NP efficiency; NPL - NPL efficiency. 
frontier. Efficiency scores associated with these models are referred to as "Overall", "NP", and "NPL", respectively.

\subsection{Does CSR Impact Banking Performance?}

Tab. 2 summarizes the mean efficiency scores for each bank under conditional and unconditional frameworks. It is evident that the conditional efficiency estimates are higher than the unconditional ones, as it should be expected due to sample restrictions under the conditional framework. We then employ the Spearman rank correlation to ascertain whether the differences between the two frameworks exist. As one can note, a significant positive correlation of 0.614 has been estimated for the overall efficiency scores, which implies that CSR has an impact on banking efficiency and, therefore, a substantive production frontier shift. As regards individual banks, the gaps in technical efficiency across conditional and unconditional frameworks are wider for large commercial banks (ICBI, CCB, $B C$, and $A B C$ ) if opposed to small and medium commercial banks (i.e., the rest of banks). Specifically, the mean gap is 0.11 for the overall efficiency scores.

We further measure the efficiency for NP-orientation and NPL-orientation to check the impact of CSR upon bank performance in regards to specific variables. The obtained rank correlation for NP $(0.553)$ is smaller than that for NPL (0.682), whereas the technical efficiency gap for NP (0.19) is larger than that for NPL (0.08). These findings imply that the CSR has a relatively stronger impact to NP than NPL.

\subsection{Disentangling the Impact}

This sub-section aims to employ a nonparametric approach to analyze the link between CSR and CFP. All of the measures considered are bounded at unity from above and therefore an increasing (decreasing) slope of the nonparametric regression relating the differences of conditional to unconditional efficiencies to $z$ variables (cf. Eq. 10) implies a positive (negative) effect of a $z$ variable upon the attainable frontier.

Fig. 1 presents a nonparametric regression plot for the technology shifts based on the overall efficiency measure. As one can note, the impact of CSR is positive up to the value of 2 . For higher values of CSR, however, we see no significant influence on the attainable technology. Indeed, the significance test (Racine, 1997; Racine et al., 2006) shows a significant relationship at the level of significance of $1 \%$. This can be explained by the fact that the influence is observed only for a certain range of CSR. For higher values of CSR one can observe certain decreases in productivity. Furthermore, confidence bounds are expanded in that region due to few observations there.

\section{Fig. 1: The impact of CSR upon the difference of conditional to unconditional overall efficiency}

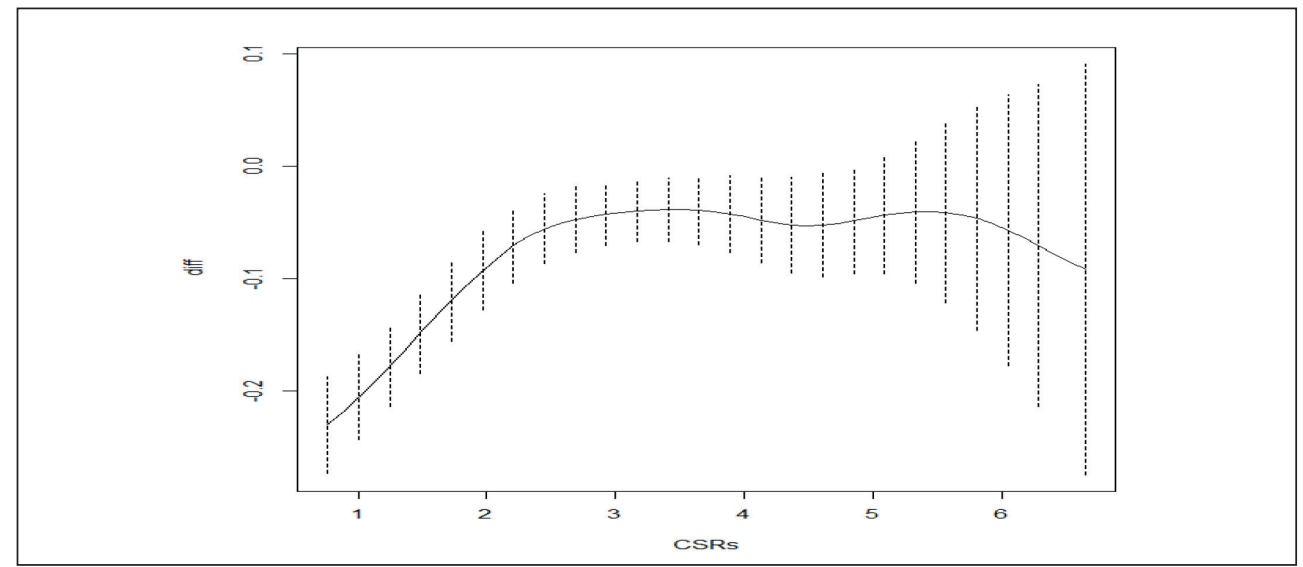




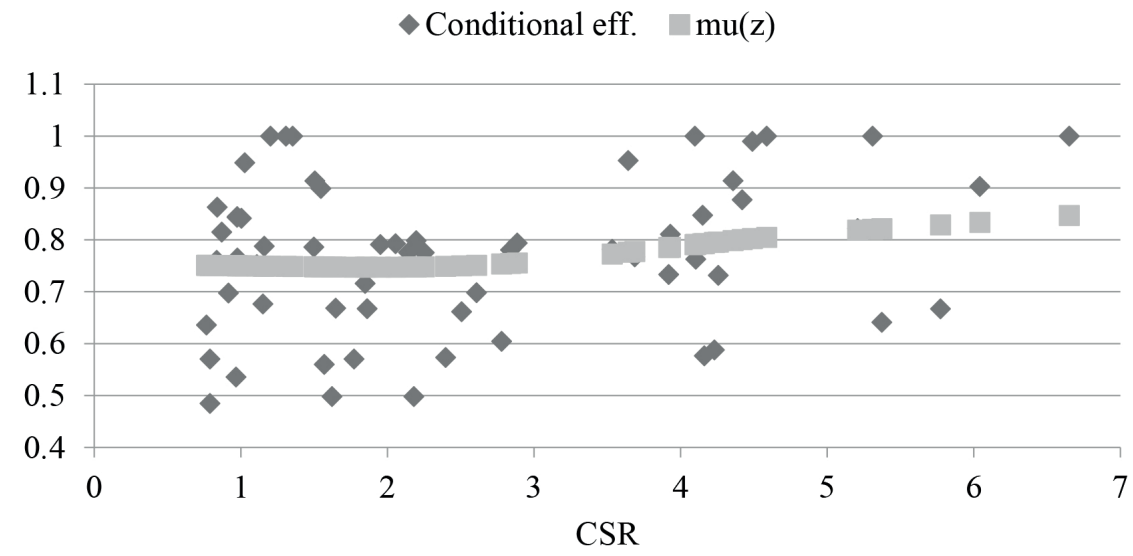

Source: own

Running a flexible regression enables to explore the relationships among the CSR and conditional efficiency thus ignoring the impact of environment a certain bank operates in.
In the context of CSR analysis, the environment can be perceived as commitments to the goals of CSR. The resulting estimates of the impact of CSR upon the conditional efficiencies,

\section{Fig. 3:} "Pure" overall efficiency

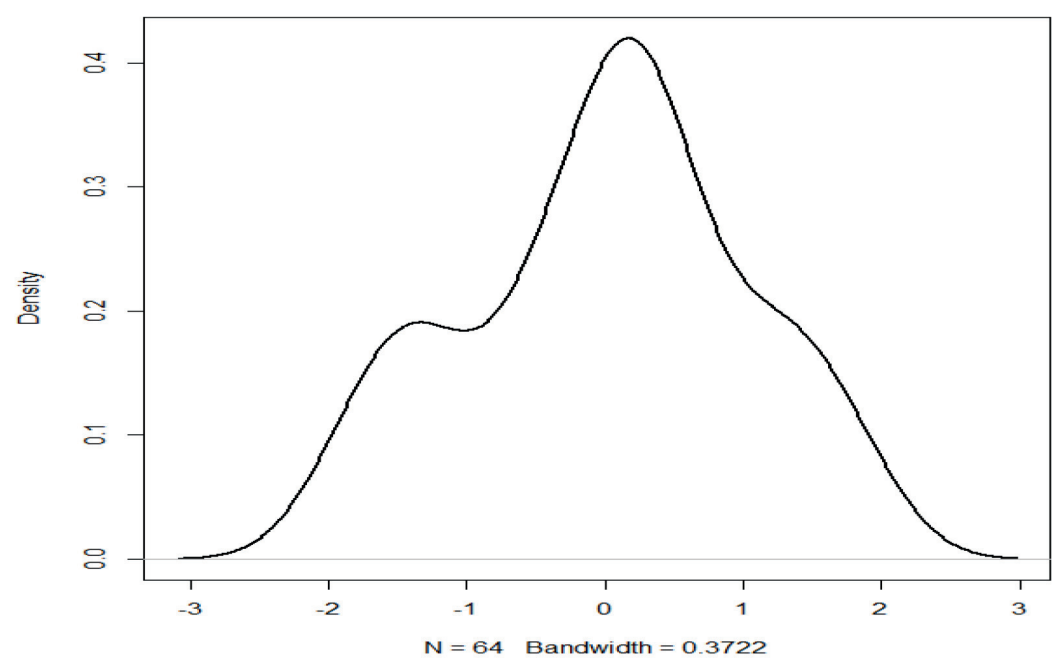


$\mu(z)$, are presented in Fig. 2. Note that a positive impact of CSR is observed for values of CSR exceeding 4. The estimates of $\sigma(z)$ follow a deceasing linear trend as $z$ increases, yet only a marginal variation in their values is observed. This implies that albeit the variance of the error term decreases along CSR, the presence of heteroskedasticity is not highly evident.

Therefore, small values of CSR stimulate productivity of the best performing banks and thus push the frontier away from the observations. However, the distribution of efficiency becomes more compact one only for larger values of CSR, viz. those exceeding 4. It can thus be concluded that increasing CSR is related to a higher homogeneity among the banks. Fig. 3 presents the kernel density of "pure" efficiency scores (note that higher values correspond to higher efficiency levels). As one can note, the distribution follows a normal distribution with a group of banks concentrated in low efficiency region. Therefore, most of the banks feature medium-level "pure" efficiency with few being extremely efficient ones.

Given the overall efficiency score (cf. Eq. 8) depends upon efficiencies associated with good and bad outputs (cf. Eqs. 6-7), we further look into relationships among CSR and NP and NPL efficiencies. Considering the shifts of attainable frontier with increasing CSR, frontier movement as captured by the NP efficiency follows a similar trend as that observed for the overall efficiency (Fig. 4). In case of NP efficiency, a positive effect upon the frontier is evident for CSR below the value of 3 . The trend is less noisy if opposed to that associated with the overall efficiency, and the relationship is significant at the level of $1 \%$. Again, certain negative effects are observed for the highest values of CSR.

As regards the effect on average efficiency, CSR had a rather marginal impact (Fig. 5). Nevertheless, a positive trend is evident with a decreasing heterogeneity in the region of the highest values of CSR.

The distribution of "pure" NP efficiency scores is close to a half-normal distribution (Fig. 6). Indeed, most of the banks maintained the relatively high "pure" NP efficiency. This shows little improvement possible in good output given the current level of CSR.

In case of the NPL efficiency, there is a U-shape relationship between CSR and the attainable frontier (Fig. 7). As this relationship is uncertain for most of the range of CSR, the $p$-value exceeds $10 \%$. Anyway, it is evident that the potential NPL performance is affected more

\section{Fig. 4: The impact of CSR upon the difference of conditional to unconditional NP efficiency}

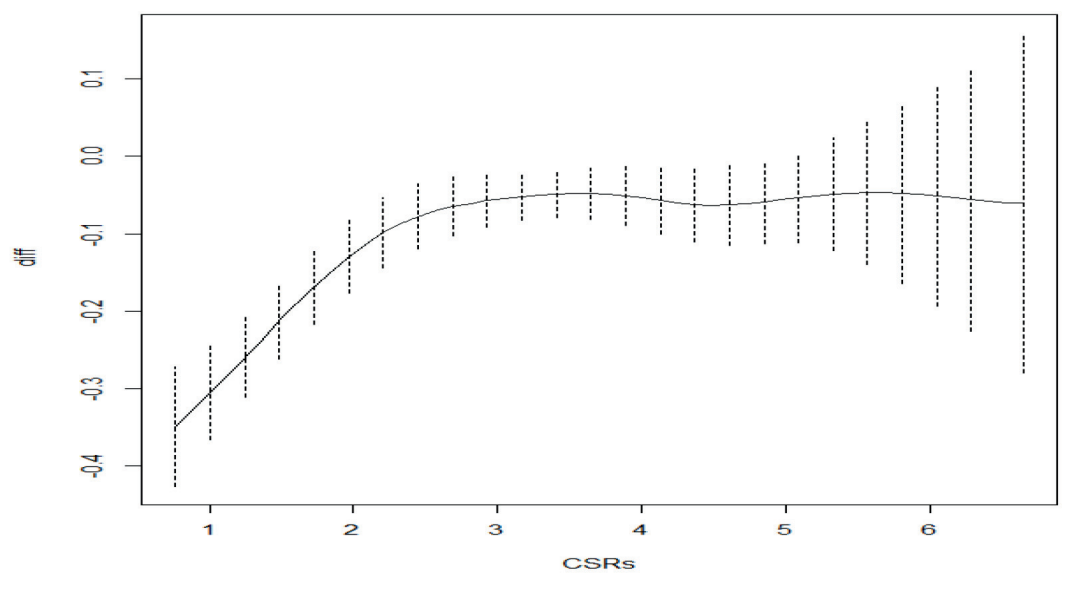




\section{Ekonomika a management}

\section{Fig. 5: The impact of CSR upon average NP efficiency}

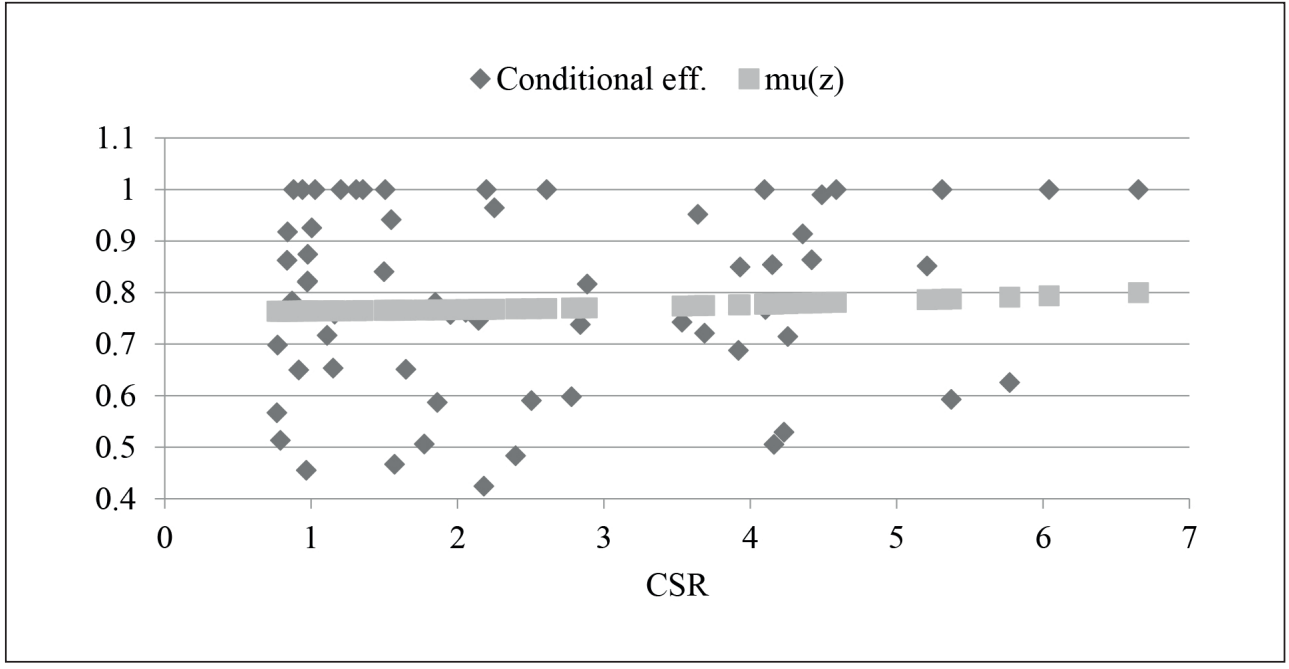

\section{Fig. 6: "Pure" NP efficiency}

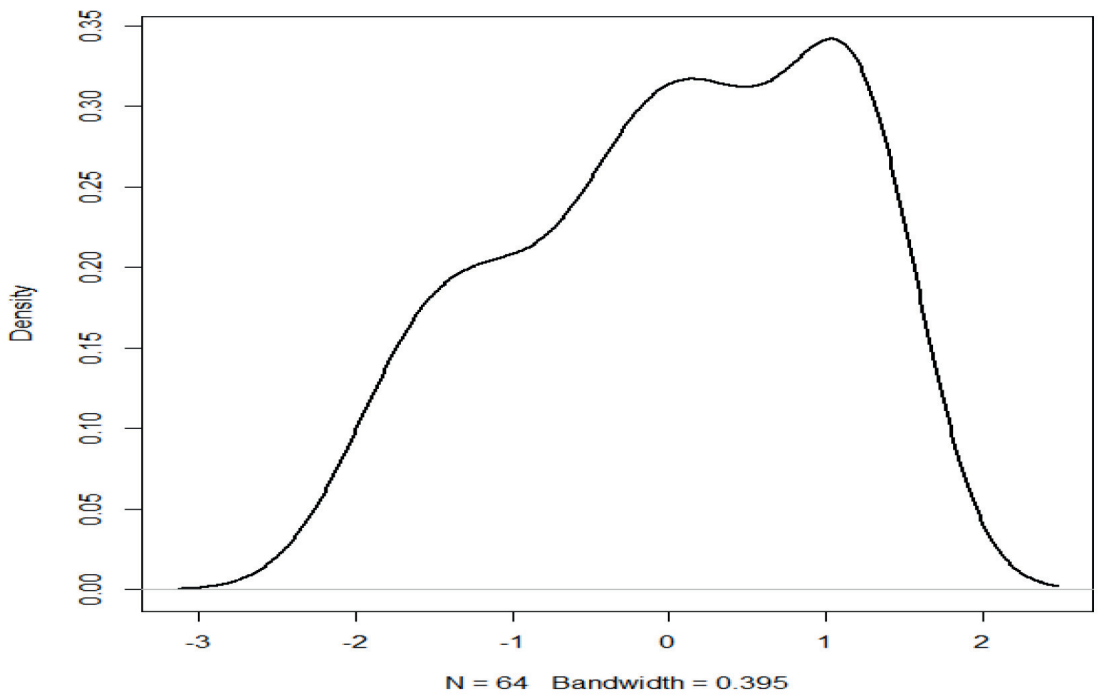

Source: own 


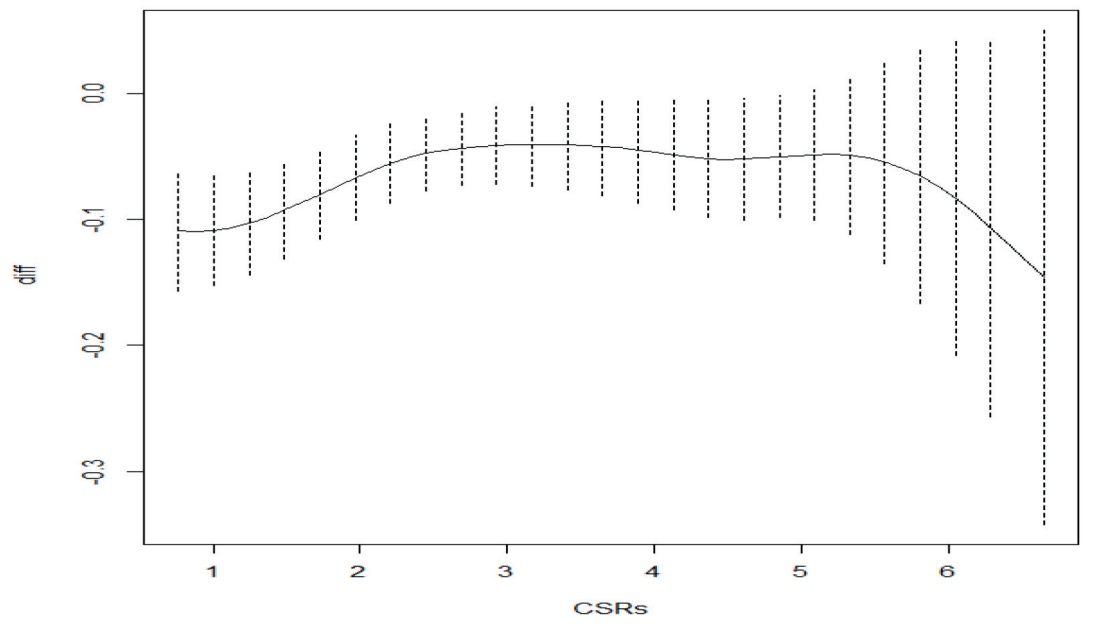

\section{Fig. 8: The impact of CSR upon average NPL efficiency}

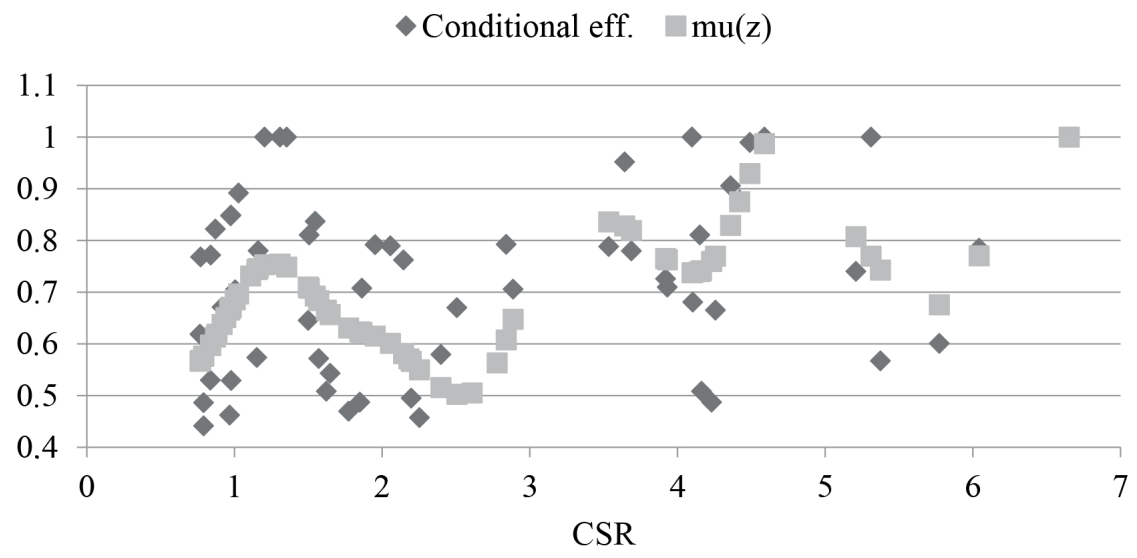


severely (in a negative way) by the highest values of CSR with confidence intervals being extremely wide.

The impact of CSR upon average conditional efficiency is rather uncertain (Fig. 8). Anyway, a more or less positive trend is evident as the CSR increases. Therefore, banks with higher CSR are more efficient than those with low one, yet relatively low performance is also possible.

The kernel density plot of "pure" NPL efficiency is depicted in Fig. 9. The distribution of "pure" NPL efficiency is close to uniform one with most of the values distributed around the average level. This suggests that banks are quite homogeneous in efficiency regarding NPL (after accounting for the effect of CSR level).

The carried out analysis, thus, implies some straightforward, yet meaningful findings. First, comparison of Figs. 1, 4, and 7 suggests that implies that a minimal increase in CSR is likely to contribute to stimulate the productivity (i.e., shift the conditional frontier). A possible

\section{Fig. 9: "Pure” NPL efficiency}

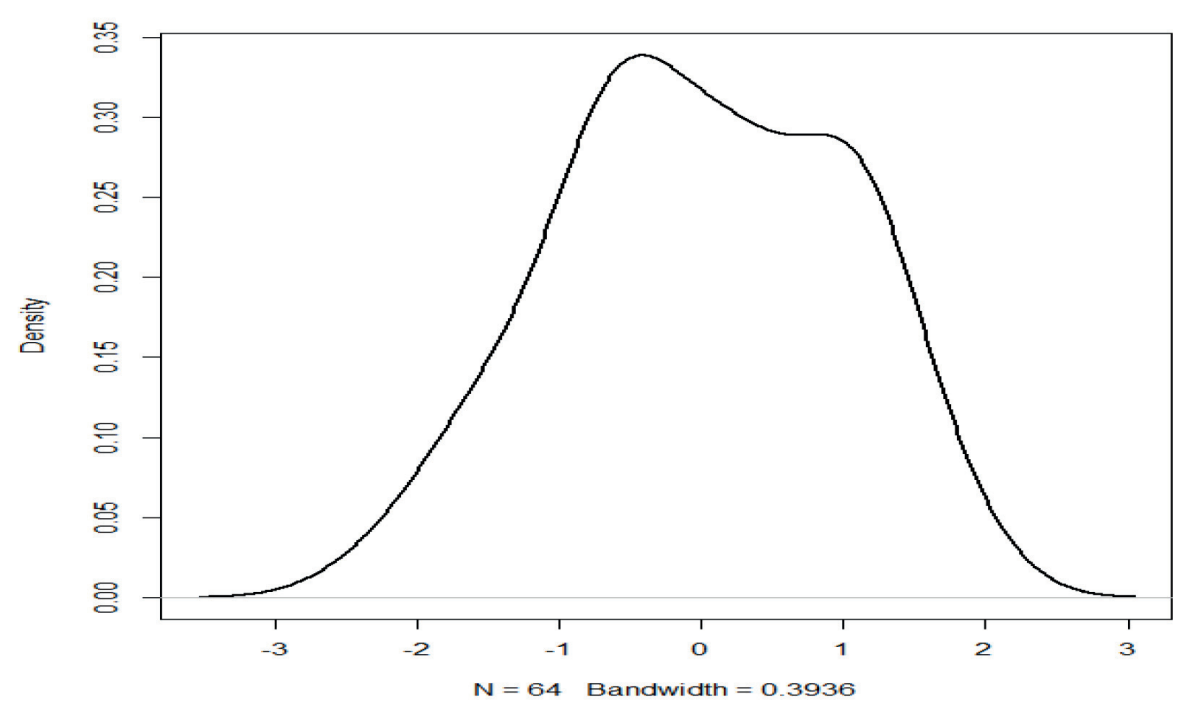

Source: own

explanation for that might be that successful activities of the bank, personnel motivation, and relatively higher remuneration are all intertwisted. However, the effect of CSR becomes negative (in terms of the conditional frontier shift) when tax, remuneration etc. expenses become too burdensome. Therefore, there is a trade-off between CSR and bank performance when a certain limit is exceeded in Chinese banking. Current trade-off here is approximately value of 3 in all three conditional models (Note that CSR is measured as a ratio of monetary flows over equity). When the CSR is lower than 3 , there is a significant increase, but when CSR is greater than 3 , the potential bank performance no longer increases and, actually, shows a decreasing trend, particularly at the highest values.

Indeed, an increasing CSR can bring both positive and negative effects simultaneously (Kang et al., 2010): at the initial phase, when the CSR is rather low (0-3), a robust growth 
in revenue (positive effect) surpasses that in costs (negative effect); however, as CSR keeps increasing ( $>3$ ), the growth in costs gradually offsets that in revenue. For example, the growth rate of NP in China Merchants Bank (CMB) is $37 \%$, when the CSR is in 2.51 , but the growth rate drops to $22 \%$ when the CSR rises to 4.49 , with most of the banks following a similar pattern.

Furthermore, it is witnessed that the impact of CSR upon NP efficiency is much more evident than that upon NPL, as shown by regression plots and data in Tab. 2. Indeed, increasing NP would directly generate more revenue, albeit decreasing NPL might require for more resources. Therefore, higher CSR is closely linked to NP, whereas its links to NPL remain less certain. Taking the China Merchants Bank as an example, one can see that under CSR of 2.51 , the growth rate of NP is $37 \%$, while that of NPL is $-3 \%$. Comparatively, when the CSR increases to 4.49 , the NP still maintains a relatively high growth rate $(22 \%)$, but the NPL adversely increases to $23 \%$, which illustrates a stronger link between CSR and NP if opposed to that between CSR and NPL.

Second, Figs. 2, 5, and 8 unanimously indicate that an increase in CSR leads to increase in the conditional efficiencies, although the latter link is not very significant in case of NPL. This basically implies an increasing homogeneity along with increasing CSR in terms of efficiency.

Third, the juxtaposition of Figs. 3, 6, and 9 reveals that banks are most efficient in turning input (fixed assets) into good output, i.e., they are able to better exploit their resources given their level of CSR. The performance in regards to contraction of NPL is less efficient. As a matter of fact, with exception for BC, BCM, and BNJ, the banks have higher "pure" NP efficiency than "pure" NPL efficiency, which is in line with previous findings of this study.

\section{Conclusion}

The results indicate that an increase in CSR generally leads towards an increase in conditional efficiency (i.e., efficiency relative to the banks with a similar level of CSR). However, the attainable frontier might be shifted to any direction for the highest values of CSR. This can be explained by the fact that CSR depends on bank revenue and costs. Therefore, high values of CSR might be the outcome of interactions of these two factors and yield uncertainty in terms of banking productivity. All in all, an increase in CSR at its minimum values undoubtedly leads to increase in efficiency in Chinese banks, whereas further effects highly depend on banks' ability to mitigate the portfolio of non-performing loans.

The analysis of "pure" efficiency indicates that more reductions in bad output are possible, as opposed to expansion of the good one. Furthermore, it turns out that CSR is likely to affect the attainable frontier in the direction of good output (net profit) rather than bad output (non-performing loans). Indeed, the portfolio of non-performing loans is difficult to reduce and therefore the impact of CSR is not significant either on the frontier or on average efficiency. Furthermore, a continuous increase in CSR might require additional revenue, which, in turn, is related to higher risk and an increase in nonperforming loan portfolio.

Unfortunately, due to data availability issues, we might have missed some relevant discussions. For example, the data for individual banks in Tab. 2 show that the technical efficiency gap between conditional and unconditional efficiencies are much larger for large commercial banks (ICBC, CCB, BC, and $A B C$ ) than for small and medium commercial banks. Accordingly, it seems meaningful to explore the impact of CSR to the two types of banks. However, due to small number of observations, we could not take that direction of research as the nonparametric regression for subgroups (21 observations for large commercial banks) was impossible. These issues, therefore, constitute an agenda for further research.

The authors gratefully acknowledge financial supports from the National Natural Science Foundation of China (71703040), the Humanities and Social Research Project of Ministry of Education in China (17YJC790215), the Fundamental Research Funds for the Central Universities (2017BQ010), and the Philosophy and Social Science Project of Guangdong Province (GD15XYJ19). 


\section{References}

Asmild, M., Hougaard, J. L., Kronborg, D., \& Kvist, H. K. (2003). Measuring Inefficiency via Potential Improvements. Journal of Productivity Analysis, 19(1), 59-76. doi:10.1023/A:1021822103696.

Asmild, M., \& Matthews, K. (2012). Multidirectional Efficiency Analysis of Efficiency Patterns in Chinese Banks: 1997-2008. European Journal of Operational Research, 219(2), 434-441. doi:10.1016/j.ejor.2012.01.001.

Asmild, M., \& Pastor, J. T. (2010). Slack Free MEA and RDM with Comprehensive Efficiency Measures. Omega, 38(6), 475-483. doi:10.1016/j.omega.2009.12.004.

Bădin, L., Daraio, C., \& Simar, L. (2010). Optimal Bandwidth Selection for Conditional Efficiency Measures: A Data-driven Approach. European Journal of Operational Research, 201(2), 633-640. doi:10.1016/j.ejor.2009.03.038.

Bădin, L., Daraio, C., \& Simar, L. (2012). How to Measure the Impact of Environmental Factors in a Nonparametric Production Model. European Journal of Operational Research, 223(3), 818-833. doi:10.1016/j.ejor.2012.06.028.

Baležentis, T., \& De Witte, K. (2015). Oneand Multi-directional Conditional Efficiency Measurement - Efficiency in Lithuanian Family Farms. European Journal of Operational Research, 245(2), 612-622. doi:10.1016/j. ejor.2015.01.050.

Berger, A. N., \& Humphrey, D. B. (1997). Efficiency of Financial Institutions: International Survey and Directions for Future Research. European Journal of Operational Research, 98(2), 175-212. doi:10.1016/S03772217(96)00342-6.

Bird, R., Hall, A. D., Momente, F., \& Reggiani, F. (2007). What Corporate Social Responsibility Activities are Valued by the Market? Journal of Business Ethics, 76(2), 189-206. doi:10.1007/s10551-006-9268-1.

Bogetoft, P., \& Hougaard, J. L. (1999). Efficiency Evaluations Based on Potential (Non-proportional) Improvements. Journal of Productivity Analysis, 12(3), 233-247. doi:10.1023/A:1007848222681.

Bowen, H. R. (1953). Social responsibilities of businessman. New York: Harper \& Row.

Bragdon, H. H., \& Marlin, J. T. (1972). Is Pollution Profitable. Risk Management, 19(2), 9-18.

Bushman, R. M., \& Wittenberg-Moerman, R. (2012). The Role of Bank Reputation in
"Certifying" Future Performance Implications of Borrowers' Accounting Numbers. Journal of Accounting Research, 50(4), 883-930. doi:10.1111/j.1475-679X.2012.00455.x.

Carroll, A. B. (1979). A Three-dimensional Conceptual Model of Corporate Performance. Academic Management Review, 4(4), 497-505.

Carroll, A. B. (2000). A Commentary and an Overview of Key Questions on Corporate Social Performance Measurement. Business \& Society, 39(4), 466-478. doi:10.1177/000765030003900406.

Cazals, C., Florens, J. P., \& Simar, L. (2002). Nonparametric Frontier Estimation: A Robust Approach. Journal of Econometrics, 106(1), 1-25. doi:10.1016/S0304-4076(01)00080-X.

Daraio, C., \& Simar, L. (2005). Introducing Environmental Variables in Nonparametric Frontier Models: A Probabilistic Approach. Journal of Productivity Analysis, 24(1), 93-121. doi:10.1007/s11123-005-3042-8.

Daraio, C., \& Simar, L. (2007). Conditional Nonparametric Frontier Models for Convex and Nonconvex Technologies: A Unifying Approach. Journal of Productivity Analysis, 28(1-2), 13-32. doi:10.1007/s11123-007-0049-3.

Daraio, C., \& Simar, L. (2014). Directional Distance and Their Robust Versions: Computational and Testing Issues. European Journal of Operational Research, 237(1), 358369. doi:10.1016/j.ejor.2014.01.064.

Daraio, C., Simar, L., \& Wilson, P. W. (2010). Testing whether two-stage estimation is meaningful in non-parametric models of production. [ISBA Discussion Papers-1031].

De Witte, K., \& Kortelaien, M. (2013). What Explains the Performance of Students in A Heterogeneous Environmental? Conditional Efficiency Estimation with Continuous and Discrete Environmental Variables. Applied Economics, 45(17), 2401-2412. doi:10.1080/0 0036846.2012.665602.

Fombrun, C., \& Shanley, M. (1990). What's in a Name? Reputation Building and Corporate Strategy. Academic of Management Journal, 33(2), 233-258. doi:10.2307/256324.

Freeman, R. E. (1984). Strategic management: A stakeholder approach. Boston: Pitman Press.

Friedman, M. (1970). The social responsibility of business is to increase its profits. Retrieved September 13, 1970, from the New York Times Magazine.

Hall, P., Racine, J. S., \& Li, Q. (2004). Cross- 
validation and the Estimation of Conditional Probability Densities. Journal of American Statistical Association, 99(468), 1015-1026. doi:10.1198/016214504000000548.

Halkos, G. E., \& Tzeremes, N. G. (2014). Public Sector Transparency and Countries and Countries' Environmental Performance: A Nonparametric Analysis. Resource \& Energy Economics, 38, 19-37. doi:10.1016/j. reseneeco.2014.06.001.

Halkos, G. E., Sundström, A., \& Tzeremes, N. G. (2015). Regional Environmental Performance and Governance Quality: A Nonparametric Analysis. Environmental Economics and Policy Studies, 17(4), 621-644. doi:10.1007/s10018-015-0106-5.

Halkos, G. E., Stern, D. I., \& Tzeremes, N. G. (2016). Population, Economic Growth and Regional Environmental Inefficiency: Evidence from US States. Journal of Cleaner Production, 112(5), 4288-4295. doi:10.1016/j. jclepro.2015.06.038.

Jeong, S. O., Park, B. U., \& Simar, L. (2010). Nonparametric Conditional Efficiency Measures: Asymptotic Properties. Annals of Operational Research, 173(1), 105-122. doi:10.1007/s10479-008-0359-5.

Kang, K. H., Lee, S., \& Huh, C. (2010). Impacts of Positive and Negative Corporate Social Responsibility Activities on Company Performance in the Hospitality Industry. International Journal of Hospitality Management, 29(1), 72-82. doi:10.1016/j.ijhm.2009.05.006.

Lee, S., \& Park, S. (2009). Do Socially Responsible Activities Help Hotel and Casino Achieve Their Financial Goals? International Journal of Hospital Management, 28(1), 105112. doi:10.1016/j.ijhm.2008.06.003.

Li, Q., \& Racine, J. S. (2008). Nonparametric Estimation of Conditional CDF and Quantile Functions with Mixed Categorical and Continuous Data. Journal of Business \& Economic Statistics, 26(4), 423-434. doi:10.1198/073500107000000250.

Margolis, J. D., \& Walsh, J. P. (2003). Misery Loves Companies: Rethinking Social Initiatives by Business. Administrative Science Quarterly, 48(2), 268-305. doi: 10.2307/3556659.

Margolis, J. D., Elfenbein, H., \& Walsh, J. (2009). Does It Pay to be Good...And Does It Matter? A Meta-Analysis and Redirection of Research on the Relationship Between Corporate Social and Financial Performance. doi:10.2139/ssrn.1866371.
McWilliams, A., \& Siegel, D. (2000). Corporate Social Responsibility and Financial Performance: Correlation or Misspecification? Strategic ManagementJournal,21(5),603-609.doi:10.1002/ (SICI)1097-0266(200005)21:5<603::AIDSMJ101>3.0.CO;2-3.

McWilliams, A., \& Siegel, D. (2001). Corporate Social Responsibility: A Theory of the Firm Perspective. Academic Management Review, 26(1), 117-127. doi:10.5465/AMR.2001.4011987.

Nadaraya, E. A. (1964). On Estimating Regression. Theory of Probability and Its Applications, 9(1), 141-142.

Ohene-Asare, K., \& Asmild, M. (2012). Banking Efficiency Analysis under Corporate Social Responsibilities. International Journal of Banking Accounting and Finance, 4(2), 146-171. doi:10.1504/IJBAAF.2012.048331.

Paul, C. J. M., \& Siegel, D. S. (2006). Corporate Social Responsibility and Economic Performance. Journal of Productivity Analysis, 26(3), 207-211. doi:10.1007/s11123-006-0016-4.

Racine, J. S. (1997). Consistent Significance Testing for Nonparametric Regression. Journal of Business \& Economic Statistics, 15(3), 369-379. doi:10.2307/1392340.

Racine, J. S., Hart, J., \& Li, Q. (2006). Testing the Significance of Categorical Predictor Variables in Nonparametric Regression Models. Econometric Reviews, 25(4), 523-544. doi:10.1080/07474930600972590.

Roman, R. M., Hayibor, S., \& Agle, B. R. (1999). The Relationship between Social and Financial Performance. Business \& Society, 38(1), 109-125. doi:10.1177/000765039903800105.

Sheikh, S. (1996). Corporate social responsibilities: Law and practice. London: Cavendish Publishing Limited.

Sheldon, O. (1923). The philosophy of management. London: Pitman Press.

Simar, L., \& Wilson, P. W. (2007). Estimation and Inference in Two-stage, Semi-parametric Model of Production Processes. Journal of Econometrics, 136(1), 31-64. doi:10.1016/j. jeconom.2005.07.009.

Simar, L., \& Wilson, P. W. (2011). Two-stage DEA: Caveat Emptor. Journal of Productivity Analysis, 36(2), 205-218. doi:10.1007/s11123011-0230-6.

Soana, M. G. (2011). The Relationship between Corporate Social Performance and Corporate Financial Performance in the Banking Sector. Journal of Business Ethics, 104(1), 133-148. doi:10.1007/s10551-011-0894-x. 


\section{Ekonomika a management}

Vitaliano, D. F., \& Stella, G. P. (2006). The Cost of Corporate Social Responsibility: the Case of the Community Reinvestment Act. Journal of Productivity Analysis, 26(3), 303-319. doi:10.1007/s11123-006-0018-2.

Watson, G. S. (1964). Smooth Regression Analysis. Sankhyā: The Indian Journal of Statistics, Series A (1961-2002), 26(4), 359-372.

Weber, M. (2008). The Business Case for Corporate Social Responsibility: A Companylevel Measurement Approach for CSR. European Management Journal, 26(4), 247261. doi:10.1016/j.emj.2008.01.006.

Winchester, M., Romaniuk, J., \& Nogomolova, S. (2008). Positive and Negative Brand Beliefs and Brand Defection/Uptake. European Journal of Marketing, 42(5/6), 553-570. doi:10.1108/03090560810862507.

Wu, M. W., \& Shen, C. H. (2013). Corporate Social Responsibility in the Banking Industry: Motives and Financial Performance. Journal of Banking \& Finance, 37(9), 3529-3547. doi:10.1016/j.jbankfin.2013.04.023.
Ning Zhu, Ph.D

South China University of Technology School of Economics and Commerce Department of Finance ningzhu@scut.edu.cn

Jelena Stjepcevic, Ph.D

Maritime Faculty in Kotor

University of Montenegro

jelena.stjepcevic@opstinakotor.com

Tomas Baležentis, Ph.D Lithuanian Institute of Agrarian Economics tomas@laei.It

Zhiqian Yu, Ph.D Guangzhou University School of Economics and Statistics Department of Economics yzq_8866@hotmail.com

Bing Wang, Ph.D Jinan University School of Economics Department of Economics twangb@jnu.edu.cn 


\title{
Abstract
}

\section{HOW DOES CORPORATE SOCIAL RESPONSIBILITY IMPACT BANKING EFFICIENCY: A CASE IN CHINA}

\author{
Ning Zhu, Jelena Stjepcevic, Tomas Baležentis, Zhiqian Yu, Bing Wang
}

Much of the earlier literature was focused on the link between corporate social responsibility and corporate financial performance, with contradictory conclusions regarding the impact of corporate social responsibility upon corporate financial performance in the literature. Departing from conventional parametric techniques, this paper employs a fully nonparametric approach to analyze the link between corporate social responsibility and corporate financial performance in Chinese banking sector. Specifically, the slack-free Multi-directional Efficiency Analysis is extended into the conditional efficiency framework. The results indicate that corporate social responsibility has a significant impact on banking performance, where an increase in CSR generally leads towards an increase in conditional efficiency, but the attainable frontier might be shifted to any direction for the highest values of corporate social responsibility. In details, the analysis of "pure" efficiency indicates that corporate social responsibility has a stronger impact on increasing net profit if compared to that on contracting the amount of non-performing loans. In other words, it turns out that corporate social responsibility is likely to affect the attainable frontier in the direction of expanding net profit rather than contracting non-performing loans, because the portfolio of non-performing loans is difficult to reduce and therefore the impact of corporate social responsibility is not significant either on the frontier or on average efficiency. However, there exists a trade-off between corporate social responsibility and bank performance when a certain limit is exceeded in Chinese banking. Thus, a minimal increase in corporate social responsibility is likely to contribute to improvements in banking performance (productivity), whereas a negative effect is observed at the highest levels of corporate social responsibility.

Key Words: Banking efficiency, corporate social responsibility, data envelopment analysis, conditional framework, multi-directional efficiency analysis.

JEL Classification: C61, D24, G21.

DOI: 10.15240/tul/001/2017-4-006 